\title{
Case study of accelerated wear of brake discs made of grey cast iron characterized by increased thermal stability
}

ARTICLE INFO

Received: 31 December 2021

Revised: 1 February 2022

Accepted: 14 February 2022

Available online: 5 March 2022
In this paper, the subject of the analysis is Rotinger High Performance brake disc, characterized by increased thermal resistance, which is a result of adequate design and material solutions. However, despite declared performance, the analyzed discs suffered accelerated wear over a period of about 20 months. The aim of this study was to assess the causes of the disc failure. As a result, it was showed that the applied material solution still does not differ from standard ones. According to the authors of this paper, an appropriate procedure to improve resistance to thermal fatigue is, among others, changing the shape of graphite precipitates from flake to spheroidal.

Key words: brake discs, thermal fatigue, thermal cracks, gray cast iron

This is an open access article under the CC BY license (http://creativecommons.org/licenses/BY/4.0/)

\section{Introduction}

Brake discs used in passenger cars are usually made of grey cast iron, which ensures dimensional stability within a wide temperature range $[2,5]$. Graphite, being the basic structural component, is characterized by high thermal conductivity, thus increasing its share in a material should ensure more intensive heat dissipation. Moreover, it also exhibits positive influence on vibration damping, sliding properties and improves features such as castability and machinability. As brake discs' temperature can be raised up to $600^{\circ} \mathrm{C}$ during high-load braking and result in wear of friction pair, fading, brake disc coning and thermal fatigue, graphite plays crucial role in transferring heat and providing the overall system efficiency [11] and its shape may be also modified to provide higher thermal resistance [9]. The most advanced discs are made of ceramics and carbon composites, which make them resistant to temperatures of up to $1000^{\circ} \mathrm{C}$. However, due to increased price, they are mainly used in racing cars and high performance vehicles. The selection of brake discs for a passenger car is based on many factors. Depending on the class of a car, its weight, intended use and price, the manufacturer equips it with a more or less advanced system.

Cast iron brake discs can be divided into monolithic, ventilated, ventilated slotted and/or drilled ones. The first of these are the least advanced. Being used in low-cost, lightweight cars, they are made of a solid piece of metal, whereby their primary drawback is tendency to heat up quickly, resulting in a drastically reduced braking force. Generally, discs are characterized by a certain heat capacity, and after reaching given temperature, the braking efficiency and heat absorption decrease significantly. Consequently, further operation in such conditions may cause irreversible damage. For this reason, new material solutions are developed [7] and discs designed for faster heat dissipation are used.

Ventilated discs have special channels in the centre of the disc that help them to transfer heat, whereby the heating time is much longer than in the case of monolithic ones [3] and they are suitable for urban roads as a result [6, 10]. Notched discs have grooves cut into the friction surface to prevent the loss of frictional force created by the accumulation of gases which block the pad from pressing properly against the disc. The grooves also evacuate dust, protect the pads from dirt and clean the surface from vitrification.

Drilled brake discs (Fig. 1) have numerous vent-holes, which continually expel the hot gases generated between disc and linings, eliminating the phenomenon of friction decay (fading). The risk of the entire braking system overheating is greatly reduced, as the hot air escapes from the surface faster. The likelihood of disc damage due to sudden temperature changes is also lowered, whereby they are used in high performance cars $[1,8]$. Moreover, friction dust is channelled through the holes and then removed by centrifugal force.

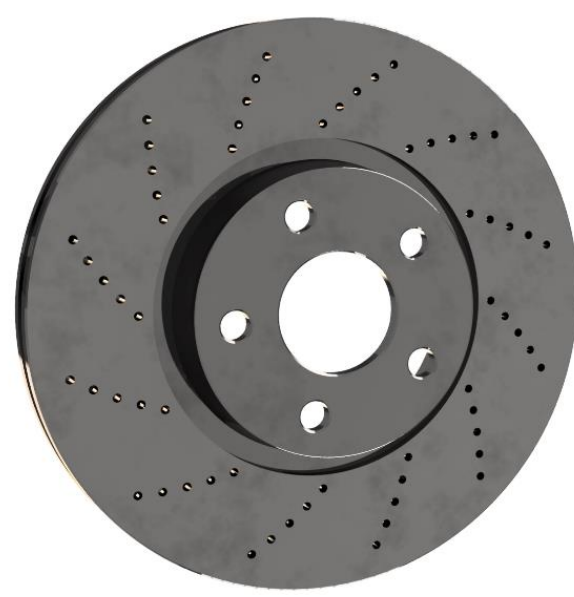

Fig. 1. Ventilated and drilled brake disc

Brake discs are elements that wear out during operation and must be replaced if their dimensions exceed the limits. Cracks running across the entire width of the friction surface are also unacceptable. The most common causes of 
disc damage include thermal cracks [4], corrosion changes and wear of a friction surface e.g. through melting of brake linings. The objective of the performed materials science analysis was to evaluate the causes of accelerated wear of brake discs. According to the manufacturer's data, they were made of a material that belongs to the high carbon class and has enriched structure. As a result, the abovementioned features should ensure higher thermal stability. However, the analysed discs were subject to accelerated wear over a period of about 20 months.

\section{Materials and methods}

A fragment of a worn Rotinger High Performance brake disc was used for tests. It was exploited for about 20 months, mainly in urban conditions (approximately 60\%) and the rest accounts for motorway. The total mileage during that period equals to $16,800 \mathrm{~km}$. The brake disc was cut out using a high-energy abrasive water-jet. Its basic geometric data are shown in Fig. 2. Moreover, additional worn out brake discs were taken for tests. Their working conditions are not specified, as they were taken from the garage to carry out comparative matallographic analysis.
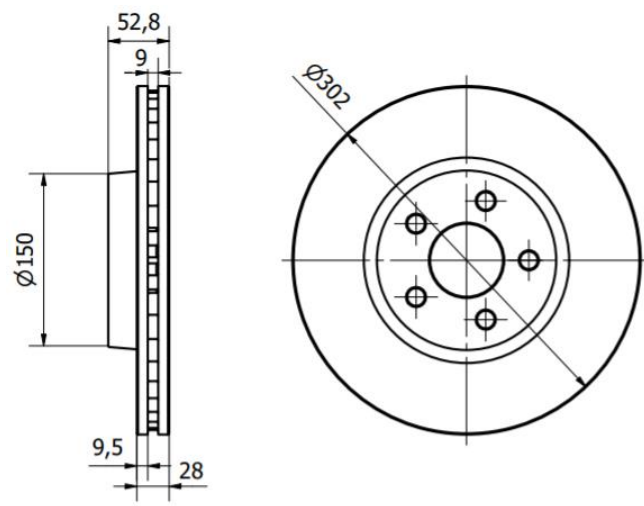

Fig. 2. Basic dimensions of the analyzed brake disc

Microscopic investigations were carried out using a Nikon AZ100 stereo microscope and a Nikon Eclipse MA200 light microscope, with magnifications ranging from 25 $500 \times$. Investigations were carried out on the material both in the non-etched state and after etching with $\mathrm{HNO}_{3}$ solution (Nital). Image registration and analysis were performed using Nikon DS-Fi2 digital camera and Nikon NIS Elements software, respectively.

Chemical composition analyses were performed by means of a GDS500A glow discharge emission analyzer from the Leco company, using the following parameters: $\mathrm{U}=1250 \mathrm{~V}, \mathrm{I}=45 \mathrm{~mA}, 99.999 \%$ argon. The results obtained were an arithmetic mean of five measurements.

The Hardness was measured using a Zwick/Roell ZHU 187.5 universal hardness tester. The Brinell method was applied, at a load of $187.5 \mathrm{kgf}(1838.7469 \mathrm{~N})$ and with a 2.5 $\mathrm{mm}$ diameter carbide ball, according to the quality standard PN-EN ISO 6506-1:2014-12.

\section{Results}

A macroscopic image of the brake disc is shown in Fig. 3. Its degree of degradation as a result of corrosion or tribological changes is relatively low, however there are charac- teristic radial cracks on the friction surface, whose main source are vent-holes (Fig. 4, 5). These types of cracks are formed when variable thermal loads occur during frequent and intensive braking, resulting in formation of internal stresses in the material. When the material is heated, its dimensions are increased as a result of thermal expansion caused by vibrations of atoms, simultaneously generating compressive stresses. Exceeding the yield point of the material due to excessive loading results in tensile stresses, which ultimately cause a break in the continuity of the material. This type of damage can cause the disc to fracture, reducing its stability and causing excessive pad wear.

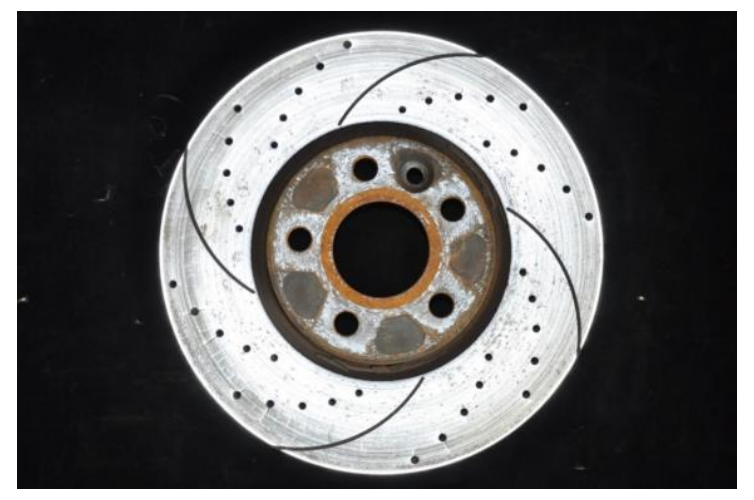

Fig. 3. Macroscopic image of the analyzed brake disc; visible venting and gas removal system through notches and holes distributed in a characteristic radial-axial manner; unetched state

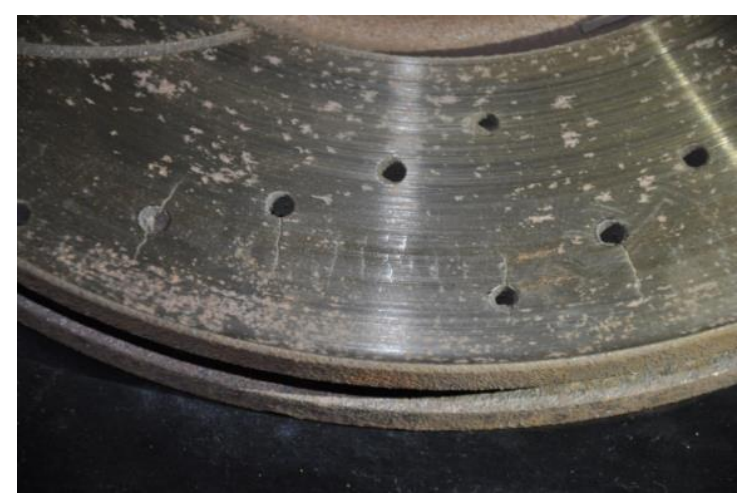

Fig. 4. Magnified section of the brake disc surface shown in Fig. 3; there can be observed radial cracks on the friction surface, which are initiated mainly at the vent-holes; unetched state

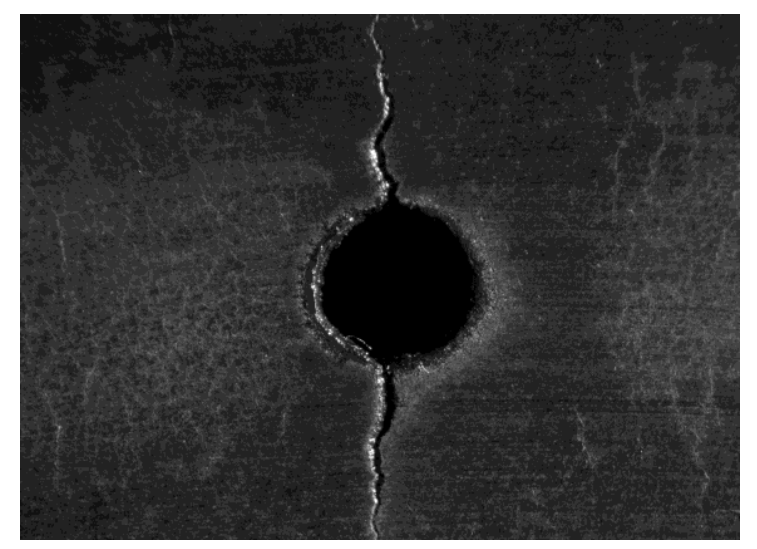

Fig. 5. Magnified section of the brake disc surface shown in Fig. 4 in the vent-hole area; visible cracks arranged in a radial way; unetched state 
Macroscopic examination of the material in the unetched state (Fig. 6,7) indicated the occurrence of unmodified flake graphite precipitates, corresponding to the standard no. I, according to PN-EN ISO 945-1:2019-09. The graphite distribution is consistent with the A standard and locally $\mathrm{C}$, while the size of the precipitates lies in the range of $2-4$, in compliance with the eight-stage scale. It should be noted here that this shape of precipitates is the most unfavorable one in terms of mechanical properties, since the sharp ends act as stress concentrators in the contact with metal matrix. This implies a significant deterioration of plastic and strength properties, including tensile strength $\mathrm{R}_{\mathrm{m}}$, flexural strength $\mathrm{R}_{\mathrm{g}}$ and torsional strength $\mathrm{R}_{\mathrm{s}}$. In fact, flake graphite has a complex three-dimensional structure and its separations violate the continuity of the cast iron metal matrix to a great extent, while not transferring any stresses. Thus, the effective cross-sectional area of the disc structure is reduced. Moreover, the longer and thinner the flakes are, the more material's internal stresses are increased. What is more, cracks running along the entire cross-section can be also observed (Fig. 6).

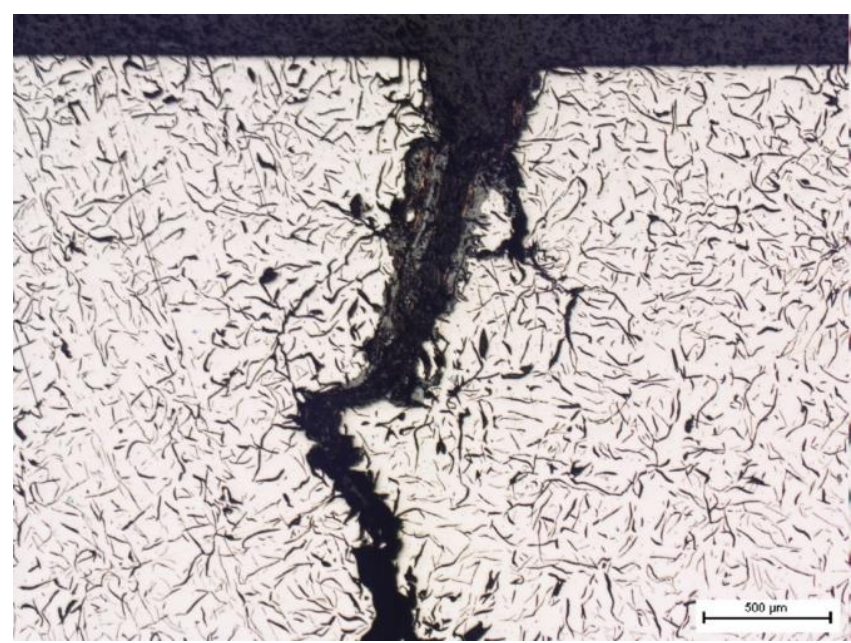

Fig. 6. Microscopic image of the analyzed brake disc. The visible crack spreads along the entire cross-section of the disc; unetched state, light microscopy

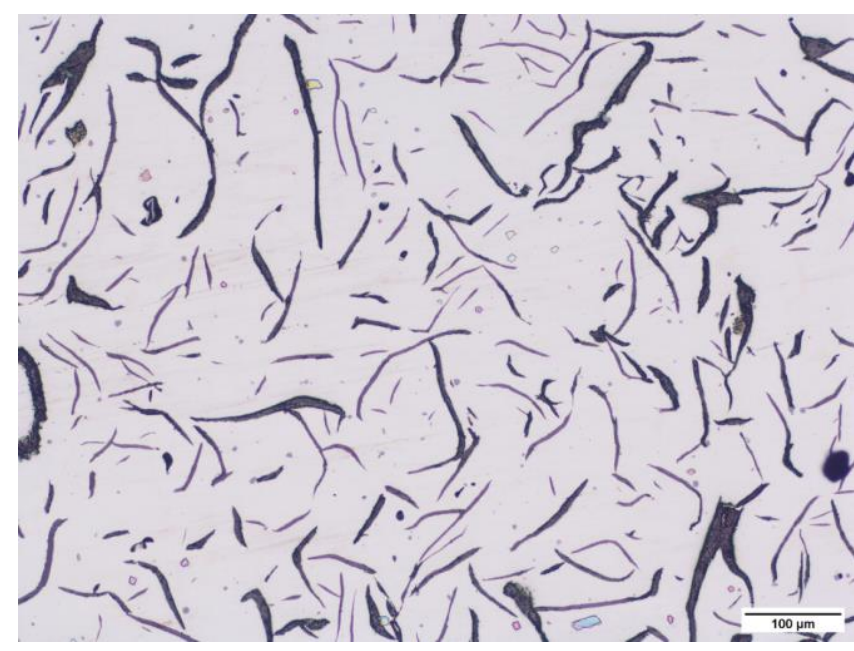

Fig. 7. Magnified image of the material structure of the analyzed brake disc shown in Fig. 6; visible flake inclusions of unmodified graphite; unetched state, light microscopy
Microscopic examination of the material in the asetched state (Fig. 8, 9) indicated the presence of a perlite matrix. The theoretical strength of perlite is approximately $\mathrm{R}_{\mathrm{m}}=750 \mathrm{MPa}$ and by binding in the matrix the highest possible content of carbon $\left(\mathrm{C}_{\mathrm{zw}}=0.77 \%\right)$, it provides relatively the highest tensile strength. At the same time, the ductile properties are reduced - for comparison, ferrite's elongation $\mathrm{A}=40 \%$ and its $\mathrm{KCU}$ impact strength is 260 $\mathrm{J} / \mathrm{cm}^{2}$. In the case of pearlite, these values are $\mathrm{A}=10 \%$ and $\mathrm{KCU}=40 \mathrm{~J} / \mathrm{cm}^{2}$, respectively.

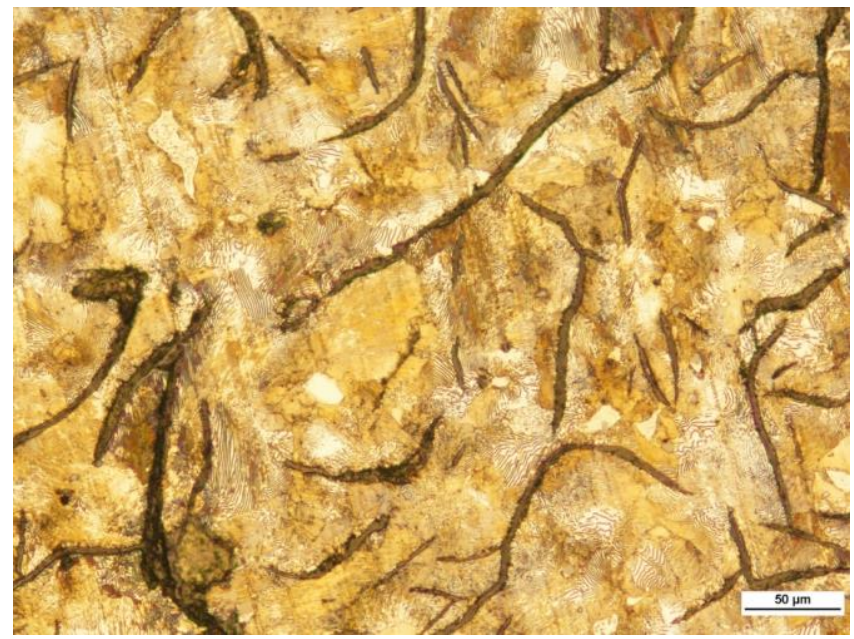

Fig. 8. Microstructure of the analyzed brake disc; visible flakes of graphite on the background of perlite matrix; precipitations of phosphite eutectic and manganese sulfides are also observed locally; light microscopy, etched with $\mathrm{HNO}_{3}$

Phosphite eutectic precipitations are visible in Fig. 9. Their shape is limited by the concave surface of previously solidified austenitic matrix. When the percentage share of phosphorus is zero, ledeburite, being a mixture of austenite and cementite, begins to crystallize at $1147^{\circ} \mathrm{C}$. As its content increases, the solidification temperature is lowered to about $950^{\circ} \mathrm{C}$, and the resulting eutectic consists of cementite, iron phosphide, and austenite, which then desintegrates into pearlite at $745^{\circ} \mathrm{C}$.

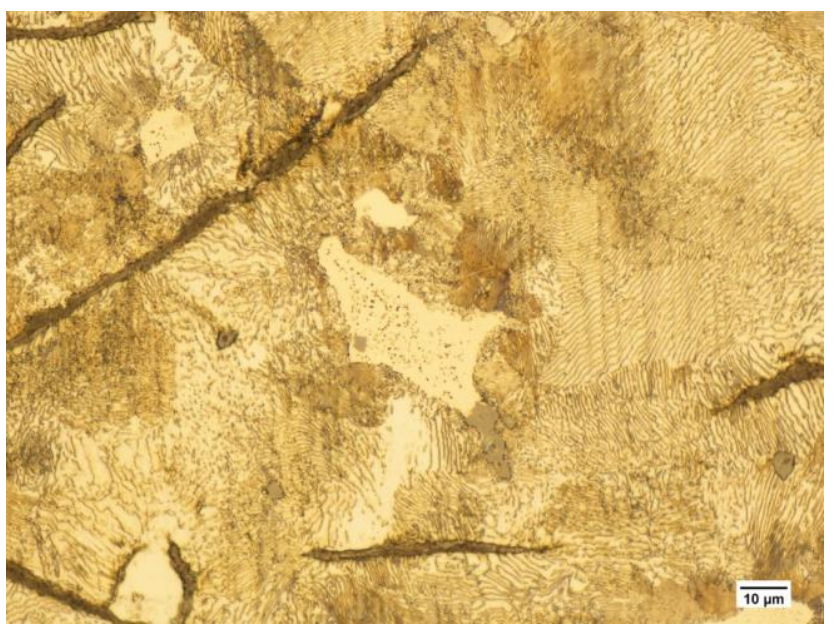

Fig. 9. Magnified image of the microstructure shown in Fig. 8; visible flakes of graphite on the background of perlite matrix; precipitations of phosphorus eutectic and manganese sulfides are also observed locally; light microscopy, etched with $\mathrm{HNO}_{3}$ 
This structure is called steadite and its occurrence may be desirable. Steadite has hardness of over $500 \mathrm{HBW}$, so that its uniform distribution in the matrix provides an increase in wear resistance. In comparison, the hardness of perlite is approximately 200-250 HBW. Steadite appears already for the content of $0.1 \% \mathrm{P}$ in the form of individual precipitates, and for the content above $0.7 \% \mathrm{P}$ it forms a continuous lattice.

Furthermore, manganese sulfide inclusions are also observed locally, whereby manganese content in the cast iron varies between 0.4 and $1.4 \%$. It is added in order to remove the disadvantageous effect of sulfur, which decreases the flowing power and thus deteriorates casting properties. The disbenefit of manganese is its strong affinity to carbon, and therefore it forms $(\mathrm{Fe}, \mathrm{Mn})_{3} \mathrm{C}$ carbides that are more durable than cementite. As a result, it whitens gray cast iron.

Table 1 shows the chemical composition of the analyzed brake disc. The percentage share of carbon is equal to $3.22 \%$, while in the case of silicon it is $1.71 \%$. According to Maurer's diagram, such a ratio of carbon to silicon content ensures the occurrence of a perlite matrix for a casting with a wall thickness of $50 \mathrm{~mm}$. Moreover, according to the Greiner-Klingenstein-Staub diagram, the total proportion of carbon and silicon equal to $4.93 \%$ results in the occurrence of a perlite matrix for wall thicknesses of 10-50 mm. Silicon is the primary graphitizing element, increasing the propensity for graphite formation during crystallization and eutectoid transformation. Furthermore, it also influences the nucleation of graphite, so that the graphite flakes are thinner and more uniformly distributed.

The phosphorus content on the level of $0.1 \%$ causes the occurrence of single precipitates of phosphite eutectic, whereas manganese in the amount of $0.57 \%$ effectively binds sulphur and does not cause whitening of gray cast iron. The addition of other elements is negligible.

The above analysis is confirmed by the results of hardness measurements performed after exploitation period (Table 2). The average value is $199 \mathrm{HBW}$, which corresponds to the hardness of perlite.

Table 1. Chemical composition of the analyzed brake disc

\begin{tabular}{|c|c|c|c|c|c|c|c|}
\hline $\mathrm{C}$ & $\mathrm{Mn}$ & $\mathrm{Si}$ & $\mathrm{P}$ & $\mathrm{S}$ & $\mathrm{Cr}$ & $\mathrm{Ni}$ & $\mathrm{Mo}$ \\
\hline \multicolumn{7}{|c|}{ Selected chemical element [\% wt.] } \\
\hline 3.22 & 0.57 & 1.71 & 0.10 & 0.07 & 0.24 & 0.06 & 0.03 \\
\hline
\end{tabular}

Table 2. Results of Brinell hardness tests

\begin{tabular}{|c|c|c|}
\hline Number of measurement & $\begin{array}{c}\text { Hardness } \\
{[\text { HBW] }}\end{array}$ & \multirow{2}{*}{ Mean value [HBW] } \\
\hline 1 & 197 & \\
\hline 2 & 203 & \multirow{2}{*}{$109 \pm 29$} \\
\hline 3 & 193 & \\
\hline 4 & 202 & \\
\hline 5 & 181 & \\
\hline 6 & 207 & \\
\hline 7 & 175 & \\
\hline 8 & 201 \\
\hline 9 & 206 \\
\hline 10 & 228 \\
\hline
\end{tabular}

Comparative material testing of a set of monolithic ventilated brake discs showed that they were made of grey cast iron and their microstructure consisted of unmodified flake graphite precipitates and a perlite matrix. Slight microstructural differences were manifested only by the size of graphite precipitates. The discs were characterized by hardness in the range of 180-206 HBW. On this basis, it can be concluded that the applied material solution for the brake discs in question does not go beyond the generally applied (standard) construction and material solutions. Figure 10 and 11 presents macroscopic images of the analysed brake discs and their microstructure in the unetched state.
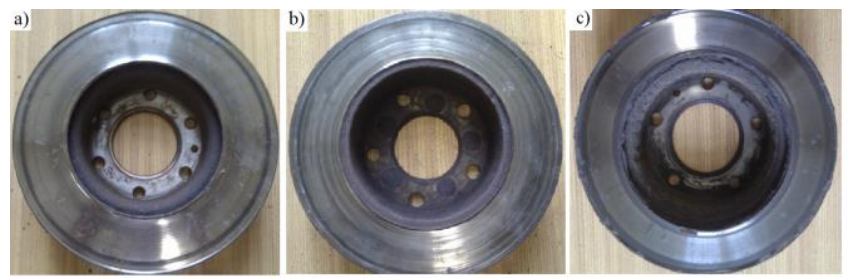

Fig. 10. Macroscopic images of comparative brake discs: a) numerous gouges occurring circumferentially on both friction surfaces, whose darker color indicates overheating; b) wear of the disc manifested by a decrease in thickness; c) wear of the disc due to corrosion changes

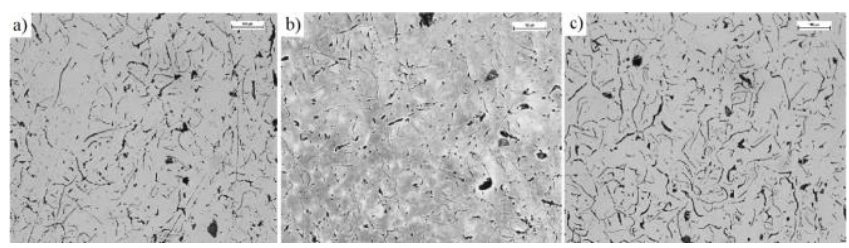

Fig. 11. Microscopic images of the analyzed brake discs shown in Fig. 10; in all cases flake precipitations of unmodified graphite are visible; they are characterized only by the variation of the size of the precipitates, and their shape and way of distribution are similar to each other; unetched state, light microscopy

\section{Conclusions}

The microstructure of the analyzed brake disc consists of flake graphite precipitates and perlite matrix, while the average hardness of the material is $199 \mathrm{HB}$. The above properties are typical for commercial brake discs. As it was declared by the manufacturer, an increased carbon content resulting in a higher proportion of graphite precipitates, was supposed to ensure stability for repeated heating and cooling. Despite the low level of wear, the disc was characterised - apart from standard tribological wear - by the occurrence of numerous cracks arranged in a radial manner. The material solution applied in the brake discs under consideration proved to be insufficient for the anticipated application in a motor vehicle. Additionally, it may be pointed out that the main source of cracks is the surface of vent-holes, where considerable corrosion changes are observed.

It should be noted that the perlite matrix, providing the highest possible strength despite the presence of graphite, at the same time shows an adverse effect on plastic and fatigue properties. According to the authors, the type and shape of graphite precipitates is also unfavorable. Flake graphite - even modified - always represents a structural notch and will act as stress concentrator. These conclusions were supported in [12], where ferritic matrix cast iron withstood 146 and 7146 thermal cycles for flake and spheroidal 
graphite, respectively. The presence of phosphorus eutectic precipitates in the matrix structure may also be of potential importance for crack propagation. During high loads, generating high temperature, the eutectic dissolves and the phenomenon of hot cracking occurs. Thereupon, further analysis should be focused primarily on the influence of graphite precipitates and phosphite eutectic on the thermal fatigue in brake discs.

\section{Nomenclature}

KCV V-notch impact strength

$\%$ wt. mass fraction

A percentage elenogation [\%]

\section{Bibliography}

[1] ATKINS, R.D., A century of high performance engine testing. Combustion Engines. 2005, 123(4), 3-18. https://doi.org/10.19206/CE-117365

[2] BAGNOLI, F., DOLCE, F., BERNABEI, M. Thermal fatigue cracks of fire fighting vehicles gray iron brake discs. Engineering Failure Analysis. 2009, 16(1), 152-163. https://doi.org/10.1016/j.engfailanal.2008.01.009

[3] BELHOCINE, A., BOUCHETARA, M. Thermal analysis of a solid brake disc. Applied Thermal Engineering. 2012, 32, 59-67. https://doi.org/10.1016/j.applthermaleng.2011.08.029

[4] DUFRENOY, P., WEICHERT, D. A thermomechanical model for the analysis of disc brakes fracture mechanism. Journal of Thermal Stresses. 2003, 26(8), 815-828.

https://doi.org/10.1080/01495730390207622

[5] GOO, B.C., LIM, C.H. Thermal fatigue evaluation of cast iron discs for railway vehicles. Procedia Engineering. 2010, 2(1), 679-685. https://doi.org/10.1016/j.proeng.2010.03.073

[6] KROPIWNICKI, B., FURMANEK, M. Analysis of the regenerative braking process for the urban traffic conditions. Combustion Engines. 2019, 178(3), 203-207.

https://doi.org/10.19206/CE-2019-335

\begin{abstract}
Martyna Zemlik, MEng. - Faculty of Mechanical Engineering, Wroclaw University of Science and Technology.

e-mail: martyna.zemlik@pwr.edu.pl
\end{abstract}

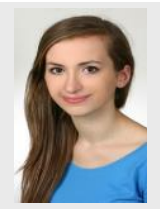

Mateusz Dziubek, MEng. - Faculty of Mechanical Engineering, Wroclaw University of Science and Technology.

e-mail: mateusz.dziubek@pwr.edu.pl

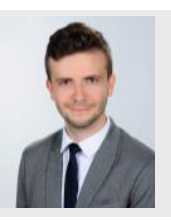

Dariusz Pyka, DEng. - Faculty of Mechanical Engineering, Wroclaw University of Science and Technology.

e-mail:dariusz.pyka@pwr.edu.pl
[7] LI, W., YANG, X., WANG, S. et al. Comprehensive analysis on the performance and material of automobile brake discs. Metals. 2020, 10(3), 377.

https://doi.org/10.3390/met10030377

[8] MERKISZ. J., PIELECHA. I., MARKOWSKI. J. Operating parameters of high performance vehicle engines. Combustion Engines. 2007, 131(4), 3-18.

https://doi.org/10.19206/CE-117313

[9] SAWCZUK, W., JÜNGST, W., ULBRICH, D. et al. Modeling the depth of surface cracks in brake disc. Materials. 2021, 14(14), 3890. https://doi.org/10.3390/ma14143890

[10] SZCZEPAŃSKI, T., SKARBEK-ŻABKIN, A. DZIEDZIAK, $P$. Impact of the road conditions on the amount of braking energy. Combustion Engines. 2017, 171(4), 265-268. https://doi.org/10.19206/CE-2017-445

[11] YAN, H.B., FENG, S.S., YANG, X.H. et al. Role of crossdrilled holes in enhanced cooling of ventilated brake discs. Applied Thermal Engineering. 2015, 91, 318-333. https://doi.org/10.1016/j.applthermaleng.2015.08.042

[12] ZYCH, J.S. Rola morfologii wydzieleń grafitu w kształtowaniu odporności na zmęczenie cieplne żeliwa. Inżynieria Materiałowa. 2015, 5(207), 343-347.

https://doi.org/10.15199/28.2015.5.30

Łukasz Konat, DEng. - Faculty of Mechanical Engineering, Wroclaw University of Science and Technology.

e-mail: lukasz.konat@pwr.edu.pl

Dominika Grygier, DSc., DEng. - Faculty of Mechanical Engineering, Wroclaw University of Science and Technology.

e-mail:dominika.grygier@pwr.edu.pl 